\title{
Comparison of propofol-hydromorphone and propofol-dexmedetomidine in patients with intubation after maxillofacial plastic surgery
}

This article was published in the following Dove Press journal:

Therapeutics and Clinical Risk Management

8 March 2016

Number of times this article has been viewed

\section{Wei Pengl,2 \\ Tiejun Zhang ${ }^{2}$ \\ Yanlin Wang'}

'Department of Anesthesiology, Zhongnan Hospital, ${ }^{2}$ Department of Anesthesiology, School and Hospital of Stomatology, Wuhan University, Wuhan, Hubei, People's Republic of China
Correspondence: Yanlin Wang Department of Anesthesiology, Zhongnan Hospital, Wuhan University, Donghu Street 169, Wuhan 43007I, Hubei,

People's Republic of China

Tel +8627876862 I5

Fax +8627876862 I5

Email yanlin_wang98@sina.com
Objective: To compare the sedation and analgesic effects between propofol-hydromorphone and propofol-dexmedetomidine in patients with postoperative intubation after maxillofacial plastic surgery.

Methods: Forty-two patients undertaking maxillofacial plastic surgery with intubation were randomly assigned into propofol plus hydromorphone $(\mathrm{P}-\mathrm{H})$ group or propofol plus dexmedetomidine ( $\mathrm{P}-\mathrm{D}$ ) group, receiving intravenous infusion of $\mathrm{P}-\mathrm{H}$ or $\mathrm{P}-\mathrm{D}$, respectively. Cerebral state index, Ramsay sedation score, arterial blood gas analysis, and physiology indices were recorded before admission (T0), 30 minutes (T1), 1 hour (T2), 2 hours (T3), 6 hours (T4), and 12 hours after admission (T5) to intensive care unit, and 10 minutes after extubation (T6). Blood interleukin-6 was measured with enzyme-linked immunosorbent assay.

Results: There was no significant difference in arterial blood gas analysis, oxygen saturation, mean arterial pressure, and respiratory rate between two groups at all time-points $(P>0.05)$. The changes of heart rate (at T4, T5, and T6), cerebral state index (T1, T2, T3, T4, and T5), and Ramsay score (at T3) in $\mathrm{P}-\mathrm{H}$ group were significantly different from that in $\mathrm{P}-\mathrm{D}$ group $(P<0.05)$. The plasma interleukin-6 at T4 in $\mathrm{P}-\mathrm{H}$ group was significantly lower than that in $\mathrm{P}-\mathrm{D}$ group $(P<0.05)$.

Conclusion: The $\mathrm{P}-\mathrm{H}$ approach takes advantages over $\mathrm{P}-\mathrm{D}$ approach in relieving the pain and discomfort, reducing the overstimulation of sympathetic nerve and the stress level, and enhancing the tolerance of postoperative intubation after maxillofacial plastic surgery.

Keywords: maxillofacial plastic surgery, intubation, hydromorphone, propofol, dexmedetomidine

\section{Introduction}

Due to the anatomical specialty, the respiratory tract is prone to be obstructed after maxillofacial surgery because of swelling and bleeding in the surgical area or larynx, or unsuitable postoperative managements. ${ }^{1}$ On the other hand, preventive tracheotomy is usually not accepted by patients and relatives, while early removal of the tracheal tube may result in lethal outcome. ${ }^{1}$ Following the rapid development of techniques in intensive care unit (ICU) and the advancement of sedation techniques, more and more patients are administrated with postoperative tracheostomy to keep spontaneous respiration, which can fasten the recovery and shorten the hospitalization time. ${ }^{2}$ However, the placement of tracheal tube raises higher requirement for anesthetist to overcome the controversy between the reservation of spontaneous respiration and the placement of tracheal tube in order to maintain suitable depth of sedation. Although anesthetists have made many efforts including administration of lidocaine gel, dexmedetomidine, and midazolam to maintain safe and comfortable tracheal tube, these approaches failed to fix the controversy. ${ }^{3,4}$ 
For a long time, the traditional sedation therapy based on hypnotics is dominant. When patients show any anxiety, the doctors usually prescribe nonanalgesic hypnotics, and prescribe analgesic medications only when patients suffer severe pain. However, hypnotics are hard to maintain patients in optional awake and calm condition, and may result in hyposedation or hypersedation, both of which have adverse effects and are not favorable for patients. Currently, it is considered that the strategy of analgesia-based sedation can effectively enhance the comfort of patients, maintain in optional sedation depth and therefore put patients through the sedation procedure in ICU under maximal physiology condition and natural sleep. 5,6

As a kind of agonist of $\mu$-opioid receptor, hydromorphone can effectively control the cardiovascular reaction to stress and maintain stable blood dynamics with slight respiration depression. $^{7}$ Propofol is a kind of short-acting agonist of $\gamma$-aminobutyric acid (GABA) and can provide good sedation effect. ${ }^{8}$ Both propofol and hydromorphone have been applied alone or with other medications in clinic, but there is no report about the co-application of these two drugs. The present study investigated if co-application of hydromorphone and propofol can improve the tolerance of postoperative intubation in patients with maxillofacial plastic surgery by comparing the effects of hydromorphone plus propofol $(\mathrm{P}-\mathrm{H})$ and propofol plus dexmedetomidine ( $\mathrm{P}-\mathrm{D})$, which will provide reference for clinical application.

\section{Materials and methods}

The study was approved by the ethic committee of the Hospital of Stomatology, Wuhan University and written informed consent forms were obtained from patients or relatives. Forty-two patients undertaking maxillofacial plastic surgery and requiring placement of postoperative intubation in ICU were recruited from July 1, 2013 to March 1, 2014. All patients (aged 18-36 years) were evaluated as grade I according to American Society of Anesthesiologists. None of these patients had history of mental or neurological diseases, history of benzodiazepines administration, or morphine addiction.

The patients were randomly allocated into $\mathrm{P}-\mathrm{H}$ group or $\mathrm{P}-\mathrm{D}$ group, 21 patients in each group. All patients were administrated with total intravenous anesthesia through general anesthesia induction with midazolam $(0.05 \mathrm{mg} / \mathrm{kg})$, sufentanil $(0.5 \mu \mathrm{g} / \mathrm{kg})$, cisatracurium besylate $(0.2 \mathrm{mg} / \mathrm{kg})$, and propofol (1-2 $\mathrm{mg} / \mathrm{kg})$, followed by placement of tracheal tube. Propofol (3-5 mg/ $\mathrm{kg} / \mathrm{h}$ ) and sufentanil (6-18 $\mu \mathrm{g} / \mathrm{kg} / \mathrm{h})$ were continuously administrated by intravenous perfusion, while cisatracurium besylate $(0.05 \mathrm{mg} / \mathrm{kg})$ was administered as necessary intravenously to maintain suitable relaxation of muscles. The anesthesia level was continuously monitored and maintained stable. The cisatracurium besylate, sufentanil, and propofol were stopped at 30, 5 , and 2 minutes prior to end of surgery, respectively. The patients were admitted into post-anesthesia care unit immediately after surgery and monitored in ICU with postoperative intubation after recovery of spontaneous respiration. After admission to ICU, patients in $\mathrm{P}-\mathrm{H}$ group were administrated with continuous perfusion of propofol $(0.5-1 \mathrm{mg} / \mathrm{kg} / \mathrm{h})$ and hydromorphone $(4-8 \mu \mathrm{g} / \mathrm{kg} / \mathrm{h})$, while patients in P-D group were administrated with continuous perfusion of propofol $(0.5-1 \mathrm{mg} / \mathrm{kg} / \mathrm{h})$ and dexmedetomidine $(0.2-0.6 \mu \mathrm{g} / \mathrm{kg} / \mathrm{h})$.

The monitored indices included: 1$)$ the heart rate (HR), mean artery pressure (MAP), peripheral capillary oxygen saturation $\left(\mathrm{SPO}_{2}\right)$, respiration rate $(\mathrm{RR})$, cerebral state index (CSI), and Ramsay score before admission of ICU (T0), 30 minutes (T1), 1 hour (T2), 2 hours (T3), 6 hours (T4), and 12 hours (T5) of admission, and 10 minutes after removal of tracheal tube (T6); 2) gas analysis of blood samples taken before removal of tracheal tube including $\mathrm{pH}$, partial pressure of $\mathrm{CO}_{2}\left(\mathrm{PaCO}_{2}\right)$, and partial pressure of $\mathrm{O}_{2}$ $\left.\left(\mathrm{PaO}_{2}\right) ; 3\right)$ related complications during sedation and after termination of medications such as respiratory depression, hypotension, tachycardia, bradycardia, nausea, vomit, agitation, and drowsiness; and 4) plasma level of interleukin-6 (IL-6) before surgery, end of surgery, 6 and 24 hours after admission to ICU, measured with enzyme-linked immunosorbent assay (ELISA) according to the manual.

\section{Statistical analysis}

Software SPSS (SPSS Inc., Chicago, IL, USA), Version 16.0, was used for statistical analysis. The measurement data were expressed as mean \pm standard deviation (SD) and compared with one-way analysis of variance for intragroup and Student's $t$-test for intergroup. The categorical data were compared with chi-square test. $P<0.05$ was set as the level of significant difference.

\section{Results}

\section{General information}

The sex, age, body weight, perioperative blood loss, surgery time, and anesthesia time were similar between the two groups, and there was no significant difference $(P>0.05$; Table 1).

Furthermore, the MAP in $\mathrm{P}-\mathrm{D}$ group was slightly decreased after admission to ICU, while the MAP in $\mathrm{P}-\mathrm{H}$ group remained stable at different time-points and there was no significant difference between the two groups $(P>0.05$; 
Table I General information of patients in the two groups

\begin{tabular}{lllllll}
\hline Group & Sex $(\mathbf{M} / \mathbf{F})$ & Age $($ years $)$ & Body weight $(\mathbf{k g})$ & Blood loss $(\mathbf{m L})$ & Surgery time $(\mathbf{m i n})$ & Anesthesia time $(\mathbf{m i n})$ \\
\hline P-H group & $8 / I 3$ & $23.1 \pm 3.4$ & $56.8 \pm 8.9$ & $459.5 \pm 167.0$ & $237.6 \pm 64.9$ & $284.5 \pm 55.8$ \\
P-D group & $10 / I I$ & $20.2 \pm 2.4$ & $55.9 \pm 6.5$ & $421.4 \pm 148.8$ & $206.2 \pm 81.3$ & $253.8 \pm 83.6$ \\
\hline
\end{tabular}

Abbreviations: P-D, propofol plus dexmedetomidine; $\mathrm{P}-\mathrm{H}$, propofol plus hydromorphone.

Table 2). The HR in P-D group was stable at T0, T1, T2, T3, $\mathrm{T} 4$, and $\mathrm{T} 5$ but slightly increased at T6. The HR in P-H group gradually increased during anesthesia and after removal of tracheal tube and there was significant difference between the two groups at T4, T5, and T6 $(P<0.05$; Table 2$)$. The $\mathrm{RR}$ was increased in both groups during anesthesia and after removal of tracheal tube, and there was no significant difference between the two groups at all time-points $(P>0.05$; Table 2).

\section{Laboratory examination}

The arterial blood gas analysis indicated that the $\mathrm{pH}, \mathrm{PaO}_{2}$, and $\mathrm{PaCO}_{2}$ between the two groups were similar and there was no significant difference before removal of the tracheal tube $(P>0.05$; Table 3$)$. In addition, the $\mathrm{SPO}_{2}$ in both groups was $100 \%$ at different time-points.

The ELISA results indicated that the blood level of IL-6 in both groups was increased at time-points of T0, T4, and 24 hours after operation when compared to that before anesthesia. Although the level of IL- 6 at 24 hours after operation was lower than that of T4, it was still slightly higher than that before anesthesia $(P>0.05)$. Furthermore, the level of IL-6 in $\mathrm{P}-\mathrm{H}$ group was significantly lower than that in $\mathrm{P}-\mathrm{D}$ group at T4 $(P<0.05$, Figure $1 \mathrm{~A})$.

\section{Function analysis}

The results indicated that the CSI in P-D group was slightly decreased after admission to ICU, then remained at low level and significantly increased after removal of the tracheal tube
$(P<0.05$; Figure 1B). In $\mathrm{P}-\mathrm{H}$ group, the CSI was gradually increased after admission to ICU, and was significantly higher than that in $\mathrm{P}-\mathrm{D}$ group at time-points of T1, T2, T3, and T4 $(P<0.05$; Figure 1B). However, there was no significant difference between the two groups after removal of the tracheal tube $(P>0.05)$.

The Ramsay sedation score indicated that the scores in both groups were significantly decreased at T2 after admission to ICU $(P<0.05)$. Furthermore, the scores of Ramsay sedation score in $\mathrm{P}-\mathrm{H}$ group were significantly higher than those of $\mathrm{P}-\mathrm{D}$ group at time-points of $\mathrm{T} 2, \mathrm{~T} 3$, T4, and T5 $(P<0.05$, Figure $1 \mathrm{C})$; however, there was no significant difference between the two groups at T6 $(P>0.05$, Figure 1C).

\section{Complications}

There were no severe complications in both two groups. Only two patients in $\mathrm{P}-\mathrm{D}$ group demonstrated sinus bradycardia with $\mathrm{HR}<50 \mathrm{bpm}$ and recovered to normal after administration with atropine. In $\mathrm{P}-\mathrm{H}$ group, only one patient incurred nausea and recovered after gastrointestinal decompression.

\section{Discussion}

For a long time, the sedation of patients in ICU mainly depends on hypnotics represented by midazolam, propofol, and dexmedetomidine, ${ }^{9}$ and analgesics are prescribed only under severe pain. Although hypnotics can attenuate the agitation and anxiety of patients, they are hard to maintain

Table 2 Physiology indices at different time-points in the two groups

\begin{tabular}{llllllll}
\hline Group & T0 & TI & T2 & T3 & T4 & T5 & T6 \\
\hline $\begin{array}{l}\text { MAP (mmHG) } \\
\text { P-H group }\end{array}$ & $74.5 \pm 10.3$ & $72.0 \pm 9.5$ & $71.6 \pm I 1.1$ & $72.3 \pm 9.4$ & $69.7 \pm 6.4$ & $69.1 \pm 7.8$ & $72.1 \pm 6.4$ \\
P-D group & $79.5 \pm 10.5$ & $75.6 \pm 11.6$ & $72.9 \pm 11.7$ & $71.8 \pm 9.6$ & $66.7 \pm 9.0$ & $66.0 \pm 8.5$ & $66.2 \pm 8.2$ \\
RR (time/min) & & & & & & 13.0 \\
P-H group & $12.8 \pm 2.5$ & $12.2 \pm 1.6$ & $12.2 \pm 2.2$ & $12.1 \pm 2.5$ & $13.8 \pm 3.4$ & $13.0 \pm 3.3$ & $14.8 \pm 2.2$ \\
P-D group & $12.6 \pm 2.4$ & $12.6 \pm 2.6$ & $13.3 \pm 2.2$ & $13.0 \pm 2.5$ & $14.7 \pm 3.5$ & $15.0 \pm 2.8$ & $16.5 \pm 3.2$ \\
HR (time/min) & & & & & & & \\
P-H group & $66.2 \pm 10$ & $66.9 \pm 9.3$ & $69.0 \pm 12.3$ & $70.9 \pm 12.2$ & $78.0 \pm 11.0^{\#}$ & $79.8 \pm 11.0^{\#}$ & $88.1 \pm 9.2^{\#}$ \\
P-D group & $69.4 \pm 10.7$ & $66.6 \pm 9.0$ & $65.3 \pm 10.1$ & $64.0 \pm 12.2$ & $65.5 \pm 12.8$ & $64.7 \pm 10.2$ & $71.3 \pm 10.7$ \\
\hline
\end{tabular}

Notes: $\# P<0.05$ vs $P-D$ group. There were two patients in the $P-D$ group who demonstrated sinus bradycardia with $\mathrm{HR}<50$ bpm but recovered after administration with atropine.

Abbreviations: HR, heart rate; MAP, mean artery pressure; P-D, propofol plus dexmedetomidine; P-H, propofol plus hydromorphone; RR, respiration rate; T0, before admission; TI, 30 minutes; T2, I hour; T3, 2 hours; T4, 6 hours; T5, 12 hours after admission; T6, 10 minutes after extubation. 
Table 3 Blood gas analysis in different groups

\begin{tabular}{lllll}
\hline Group & $\mathbf{S P O}_{2}$ & $\mathbf{P a O}_{2}$ & $\mathbf{P a C O}_{2}$ & $\mathbf{p H}$ \\
\hline P-H group & 100 & $191.1 \pm 71.1$ & $43.3 \pm 6.0$ & $7.35 \pm 0.03$ \\
P-D group & 100 & $190.0 \pm 61.2$ & $42.3 \pm 4.3$ & $7.38 \pm 0.03$
\end{tabular}

Abbreviations: $\mathrm{PaCO}_{2}$, partial pressure of $\mathrm{CO}_{2} ; \mathrm{PaO}_{2}$, partial pressure of $\mathrm{O}_{2}$; $\mathrm{P}-\mathrm{D}$, propofol plus dexmedetomidine; $\mathrm{P}-\mathrm{H}$, propofol plus hydromorphone; $\mathrm{SPO}_{2}$, peripheral capillary oxygen saturation.

patients in optional awake and comfortable conditions and easily result in hypersedation or hyposedation, which leads to other complications. The America adult ICU guideline (2013 version) $)^{20}$ recommends propofol and dexmedetomidine as first-line analgesics. Single use of propofol is prone to induce hypotension, respiratory depression, and hypertriglyceridemia, even propofol infusion syndrome at high dosage, ${ }^{10}$ while dexmedetomidine as $\alpha 2$-adrenoreceptor agonist rarely displays respiratory depression but has large effect on HR. ${ }^{11}$ Therefore, the present study set $\mathrm{P}-\mathrm{D}$ as control and found that neither $\mathrm{P}-\mathrm{D}$ nor $\mathrm{P}-\mathrm{H}$ has significant effect on $\mathrm{SPO}_{2}$ or MAP. Furthermore, we found that the HR in $\mathrm{P}-\mathrm{H}$ group was significantly higher than that in $\mathrm{P}-\mathrm{D}$ group and there were two patients in the $\mathrm{P}-\mathrm{D}$ group who demonstrated sinus bradycardia during sedation and recovered after administration with atropine. These results are consistent with previous study ${ }^{12}$ and suggest that the $\mathrm{P}-\mathrm{D}$ approach may have a potential medical risk for patients suffering preoperative bradycardia, while the $\mathrm{P}-\mathrm{H}$ approach may be a better choice for these patients.

The stimuli of intubation to the larynx and tracheostomy are considered as strong noxious and can be intolerable. ${ }^{13}$ Even the patient with short-term placement of postoperative tracheal tube may have no clear pain, the stimuli still can result in severe complications such as cardiac ischemia and arrhythmia. ${ }^{14}$ Aicher et $\mathrm{l}^{15}$ found that, in the cell membrane of ventral lateral medulla controlling the sympathetic cardiac activity and the vasoconstrictive function, there is dense $\mu$-opioid receptor, which could reduce myocardial excitation and decrease blood pressure. Hydromorphone is an agonist of $\mu$-opioid receptor, having eight to ten folds of analgesic effect of morphine and lower addiction, and therefore has been applied in postoperative pain and chronic cancer pain with confirmed clinical safety and effect in modulating the emotional response of patients. ${ }^{16}$ The present study found that there is no significant change in RR in both two groups,
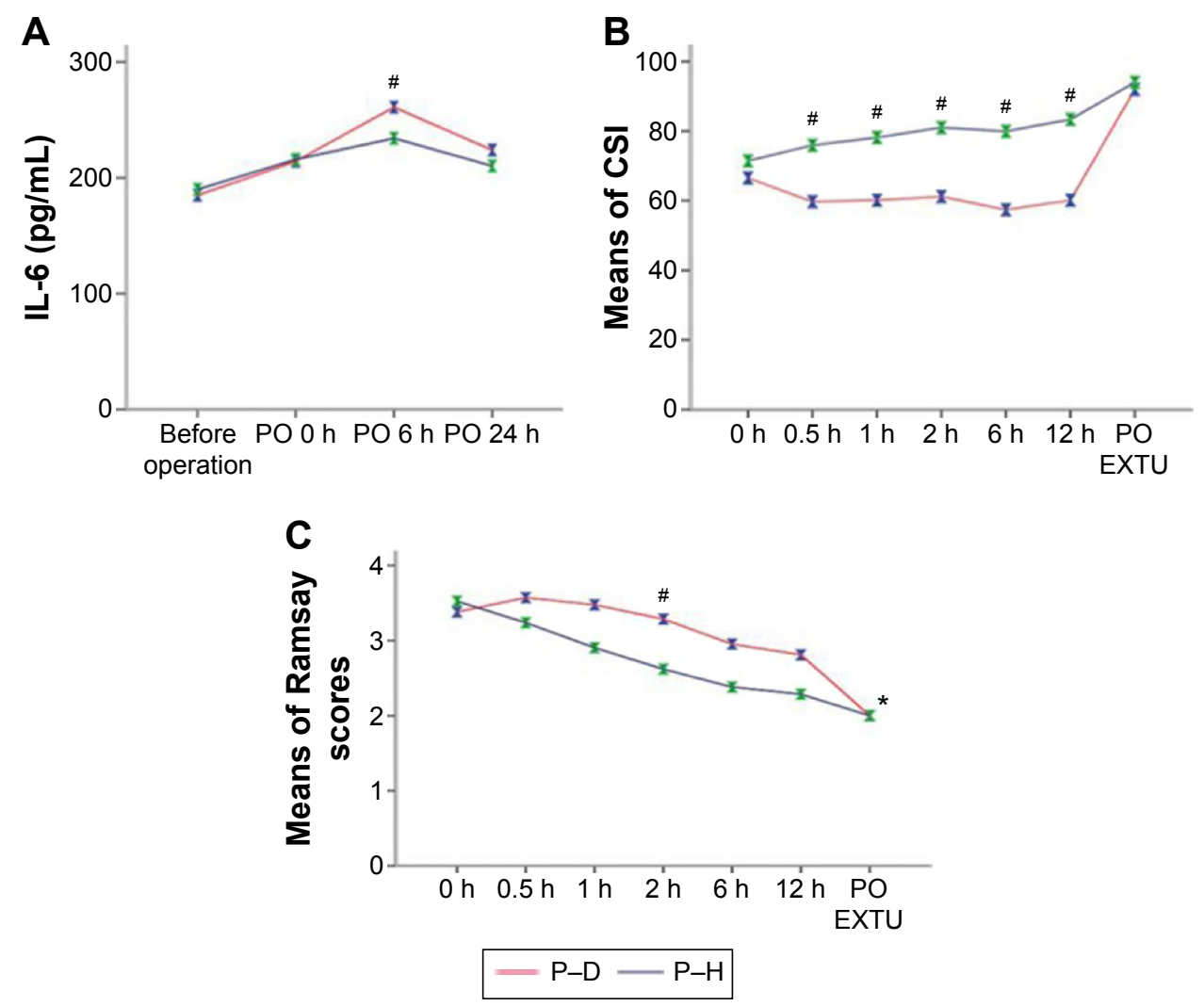

Figure I Comparison of IL-6 by ELISA (A), CSI (B), and Ramsay sedation score (C) between P-H group and P-D group at different time-points. Notes: ${ }^{*} P<0.05$ vs T0, ${ }^{*} P<0.05$ vs $P-D$ group.

Abbreviations: CSI, cerebral state index; ELISA, enzyme-linked immunosorbent assay; IL-6, interleukin-6; P-D, propofol plus dexmedetomidine; P-H, propofol plus hydromorphone; PO EXTU, post-extubation. 
or significant difference in blood gas analysis between the two groups, suggesting that the $\mathrm{P}-\mathrm{H}$ approach has minimum effect on the respiration of patients undertaking maxillofacial plastic surgery and would not produce respiration depression.

The Ramsay sedation scale and CSI are indices monitoring the sedation extent during placement of tracheal tube to avoid the adverse events. ${ }^{17,18}$ In the present study, we found that the Ramsay sedation score in $\mathrm{P}-\mathrm{H}$ group was lower than that in P-D group, while the CSI was higher than that in $\mathrm{P}-\mathrm{D}$ group, suggesting that $\mathrm{P}-\mathrm{H}$ can maintain patients in more conscious and calm conditions to endure the placement of tracheal tube and undertake the sedation. The advantages of the $\mathrm{P}-\mathrm{H}$ approach obviously meet well with the analgesia-based sedation and are favorable for the patients. ${ }^{5,6}$ In addition, the stress induced by placement of postoperative tracheal tube can aggravate the inflammation, while hypnotics have been validated to block the effect. ${ }^{19}$ Consistently, the ELISA results indicated that the IL-6 level in P-H group was lower than that in P-D group at 6 and 24 hours after admission to ICU. These results suggest that the $\mathrm{P}-\mathrm{H}$ approach has advantages over the $\mathrm{P}-\mathrm{D}$ approach in reducing the inflammatory reaction of the body and inhibiting the stress reaction of larynx through sedative effects.

In summary, the $\mathrm{P}-\mathrm{H}$ approach fully displays the sedative effect of propofol and anti-inflammation/analgesic effect of hydromorphone in patients with postoperative tracheal intubation after maxillofacial plastic surgery. Simultaneously, the $\mathrm{P}-\mathrm{H}$ approach has fewer disturbances on the spontaneous respiration and cardiac system through maintaining the patients in conscious and comfortable conditions to finish the sedation in ICU.

\section{Disclosure}

The authors report no conflicts of interest in this work.

\section{References}

1. Orr DL II. The development of anesthesiology in oral and maxillofacial surgery. Oral Maxillofac Surg Clin North Am. 2013;25:341-355.

2. Chen J, Zhou JQ, Chen ZF, Huang Y, Jiang H. Efficacy and safety of dexmedetomidine versus propofol for the sedation of tube-retention after oral maxillofacial surgery. J Oral Maxillofac Surg. 2014;72(2):285.
3. Ohata H, Tanemura E, Dohi S. Use of high-dose dexmedetomidine infusion for anesthesia and sedation in a patient for microlaryngeal surgery maintained with spontaneous breathing. Masui. 2008;57:428-432.

4. Gupta S, Singh D, Sood D, Kathuria S. Role of dexmedetomidine in early extubation of the intensive care unit patients. J Anaesthesiol Clin Pharmacol. 2015;31:92-98.

5. Bugedo G, Tobar E, Aguirre M, et al. The implementation of an analgesia-based sedation protocol reduced deep sedation and proved to be safe and feasible in patients on mechanical ventilation. Rev Bras Ter Intensiva. 2013;25:188-196.

6. Devabhakthuni S, Armahizer MJ, Dasta JF, Kane-Gill SL. Analgosedation: a paradigm shift in intensive care unit sedation practice. Ann Pharmacother. 2012;46:530-540.

7. Clemens KE, Likar R. Versatility of different pharmaceutical formulations of hydromorphone in the management of severe cancer pain and pain in palliative care. Pain Manag. 2013;3:369-375.

8. Aghdaii N, Yazdanian F, Faritus SZ. Sedative efficacy of propofol in patients intubated/ventilated after coronary artery bypass graft surgery. Anesth Pain Med. 2014;4:e17109.

9. Turunen H, Jakob SM, Ruokonen E, et al. Dexmedetomidine versus standard care sedation with propofol or midazolam in intensive care: an economic evaluation. Crit Care. 2015;19:67.

10. Vasile B, Rasulo F, Candiani A, Latronico N. The pathophysiology of propofol infusion syndrome: a simple name for a complex syndrome. Intensive Care Med. 2003;29:1417-1425.

11. Hammer GB, Drover DR, Cao H, et al. The effects of dexmedetomidine on cardiac electrophysiology in children. Anesth Analg. 2008;106:79-83.

12. Erdman MJ, Doepker BA, Gerlach AT, Phillips GS, Elijovich L, Jones GM. A comparison of severe hemodynamic disturbances between dexmedetomidine and propofol for sedation in neurocritical care patients. Crit Care Med. 2014;42:1696-1702.

13. De Jonghe B, Bastuji-Garin S, Fangio P, et al. Sedation algorithm in critically ill patients without acute brain injury. Crit Care Med. 2005;33: 120-127.

14. Irwin RS. Complications of cough: ACCP evidence-based clinical practice guidelines. Chest. 2006;129:54S-58S.

15. Aicher SA, Kraus JA, Sharma S, Patel A, Milner TA. Selective distribution of mu-opioid receptors in $\mathrm{C} 1$ adrenergic neurons and their afferents. J Comp Neurol. 2001;433:23-33.

16. Stauble ME, Moore AW, Langman LJ, et al. Hydrocodone in postoperative personalized pain management: pro-drug or drug? Clin Chim Acta. 2014;429:26-29.

17. Yang KS, Habib AS, Lu M, et al. A prospective evaluation of the incidence of adverse events in nurse-administered moderate sedation guided by sedation scores or Bispectral index. Anesth Analg. 2014;119: $43-48$.

18. Zhang L, Xu L, Zhu J, et al. To clarify features of photoplethysmography in monitoring balanced anesthesia, compared with Cerebral State Index. Med Sci Monit. 2014;20:481-486.

19. Naguib AN, Tobias JD, Hall MW, et al. The role of different anesthetic techniques in altering the stress response during cardiac surgery in children: a prospective, double-blinded, and randomized study. Pediatr Crit Care Med. 2013;14:481-490.

20. Barr J, Fraser GL, Puntillo K, et al. Clinical Practice Guidelines for the Management of Pain, Agitation, and Delirium in Adult Patients in the Intensive Care Unit. Crit Care Med. 2013;41:263-306.

\section{Publish your work in this journal}

Therapeutics and Clinical Risk Management is an international, peerreviewed journal of clinical therapeutics and risk management, focusing on concise rapid reporting of clinical studies in all therapeutic areas, outcomes, safety, and programs for the effective, safe, and sustained use of medicines. This journal is indexed on PubMed Central, CAS,

\section{Dovepress}

EMBase, Scopus and the Elsevier Bibliographic databases. The manuscript management system is completely online and includes a very quick and fair peer-review system, which is all easy to use. Visit http://www.dovepress.com/testimonials.php to read real quotes from published authors. 